\title{
Blunt Neck Trauma at a Level I Trauma Centre: A Six-Year Experience at the
}

Queen Elizabeth Hospital Birmingham

B.A. Zakaria ${ }^{1,2}$, J. Muzaffar ${ }^{2,3}$, L.E. Orr ${ }^{2,3}$, C.J. Coulson ${ }^{1,2}$, N. Sharma ${ }^{1,2}$

${ }^{1}$ University of Birmingham, ${ }^{2}$ University Hospitals Birmingham NHS Foundation Trust, ${ }^{3}$ Royal Centre for Defence Medicine

\section{Introduction}

Blunt neck trauma describes an injury to the anterior neck that does not breach platysma. Although comprising less than $1 \%$ of blunt external trauma admissions ${ }^{(1)}$, mortality in blunt neck trauma can be as high as $40 \%{ }^{(2)}$. Morbidity can also be significant, affecting phonation, deglutition, and ventilation. The majority of blunt neck trauma is secondary to road traffic accidents(3). Other mechanisms include assault, falls, hanging and strangulation, and sporting injuries $^{(1)}$.

\section{Aims}

1. To report the experience of blunt neck trauma at a UK Level I trauma centre.

2. To assess the degree of correlation between 'hot' imaging reports and consultant imaging reports.

3. To assess the degree of correlation between imaging reports and operative findings.

\section{Methods}

Study design: Retrospective case note review

Inclusion criteria:

- Blunt trauma to the anterior neck

Exclusion criteria:

- Neck trauma breaching platysma

- Isolated cervical spine trauma

\begin{tabular}{|c|}
\hline $\begin{array}{c}\text { Potential cases between } 01^{\text {st }} \text { January } 2011 \text { and } 31^{\text {st }} \text { December } 2017 \\
\text { identified by medical coding }\end{array}$ \\
$\begin{array}{c}2386 \text { patient notes retrospectively assessed for } \\
\text { inclusion }\end{array}$ \\
\hline $\begin{array}{c}17 \text { blunt neck trauma cases included } \\
\text { imaging reports, operative reports, discharge letters, follow-up } \\
\text { appointments) }\end{array}$ \\
$\qquad \begin{array}{c}2369 \text { cases } \\
\text { excluded }\end{array}$ \\
\hline Data analysis using IBM SPSS Statistics \\
Results
\end{tabular}

Patient Demographics and Mechanism of Injury:

$12(70.6 \%)$ patients were male and 5 (29.4\%) were female. The median age was 40.6 years (range, $21.5-70.3$ years).

\begin{tabular}{|l|c|c|}
\hline Mechanism of Injury & Frequency & Percentage of Injuries (\%) \\
\hline Road Traffic Accident & 7 & 41.2 \\
\hline Fall from Bicycle & 3 & 17.6 \\
\hline Hanging & 3 & 17.6 \\
\hline Blunt Assault & 2 & 11.8 \\
\hline Lacrosse Ball & 1 & 5.9 \\
\hline Strangulation & 1 & 5.9 \\
\hline
\end{tabular}

\section{Physical Examination:}

Most patients presented neurologically intact (see chart below). Polytrauma was common, shown by the presence of head injuries in $52.9 \%$ of patients.

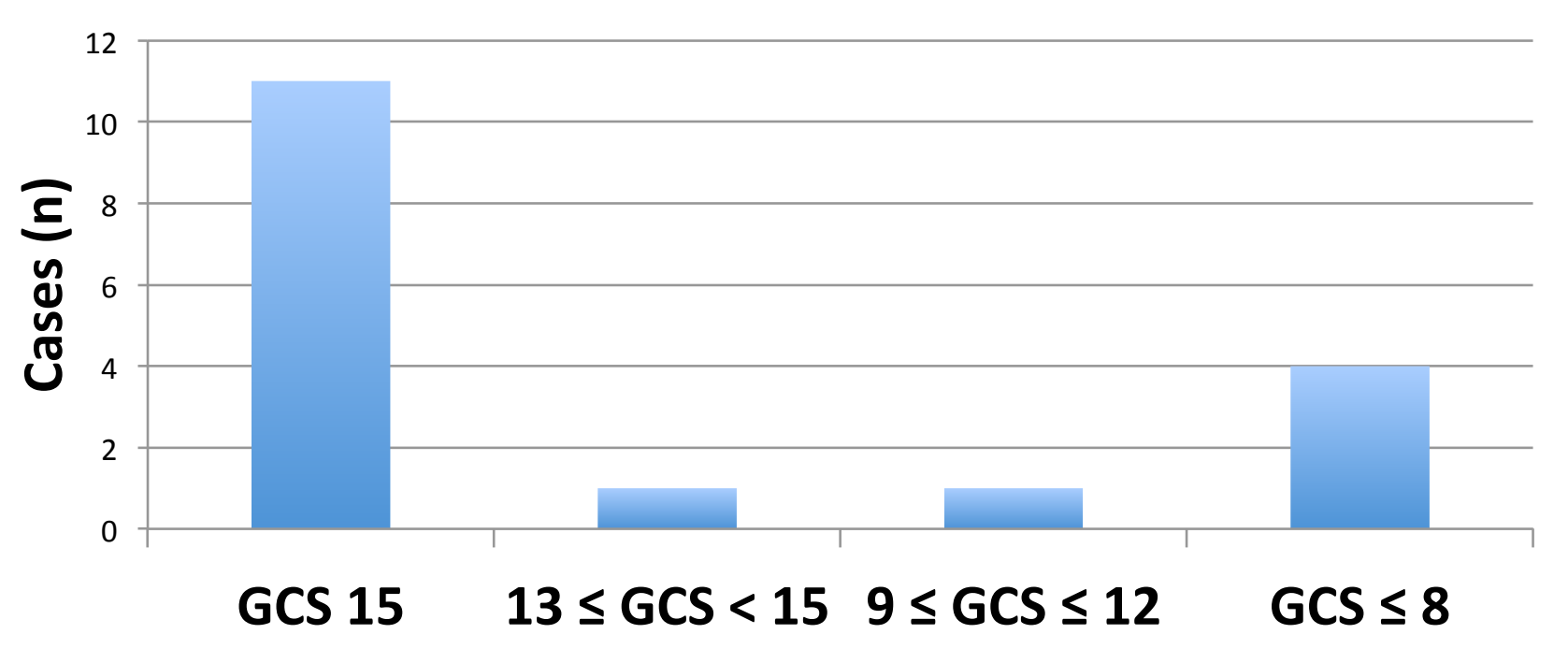

Imaging:

CT head was performed in 11 (64.7\%) patients whilst MDCTA was performed in 9 (52.9\%). Whole-body trauma CTs, often used following road traffic accidents, were performed in 7 (41.2\%) patients.

The 'hot' reports and consultant reports matched for all head and neck imaging procedures apart from one (11.1\%) MDCTA neck, and one (9.1\%) CT head.

Imaging reports did not match operative findings in 2 out of 5 (40\%) patients where imaging failed to identify a submandibular gland injury and brachial plexus avulsion.

\section{Definitive Management:}

6 patients underwent surgical exploration but only 4 of these were positive for internal injuries (see chart below).

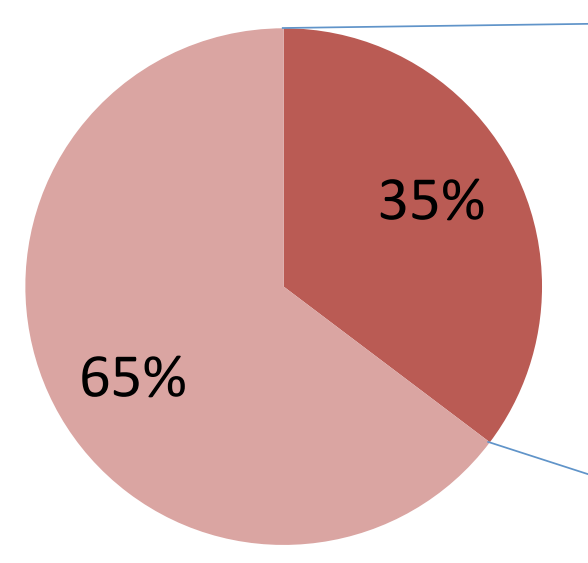

- Surgical Exploration

Conservative Management

\section{Morbidity and Mortality:}

Survival was $100 \%$ and no patient required tracheostomy on discharge or had a missed injury.

\section{Conclusion}

Blunt neck trauma is a rare presentation affecting predominantly male patients following road traffic accidents. Polytrauma is common and patients can present with neurological impairments following associated head injuries. Inexperience in reporting trauma scans does not influence their accuracy. However, when compared to operative findings, imaging studies missed significant glandular and nervous injuries. An evidence-based management guideline would help reduce negative explorations by identifying specific indications for exploration. 